\title{
ARTICLE \\ LW-213, a newly synthesized flavonoid, induces G2/M phase arrest and apoptosis in chronic myeloid leukemia
}

Xiao Liu ${ }^{1}$, Po Hu${ }^{1}$, Hui $\mathrm{Li}^{1}$, Xiao-xuan $\mathrm{Yu}^{1}{ }^{1}$, Xiang-yuan Wang ${ }^{1}$, Ying-jie Qing ${ }^{1}$, Zhan-yu Wang ${ }^{1}$, Hong-zheng Wang ${ }^{1}$, Meng-yuan Zhu ${ }^{1}$, Qing-long Guo ${ }^{1}$ and Hui Hui ${ }^{1}$

Chronic myeloid leukemia (CML) is a clonal hematopoietic stem cell neoplasm characterized by an uncontrolled proliferation of moderately and well differentiated cells of the granulocytic lineage. LW-213, a newly synthesized flavonoid compound, was found to exert antitumor effects against breast cancer through inducing G2/M phase arrest. We investigated whether LW-213 exerted anti-CML effects and the underlying mechanisms. We showed that LW-213 inhibited the growth of human CML cell lines K562 and imatinid-resistant K562 (K562r) in dose- and time-dependent manners with $\mathrm{IC}_{50}$ values at the low $\mu \mathrm{mol} / \mathrm{L}$ levels. LW-213 (5, 10, $15 \mu \mathrm{M}$ ) caused $\mathrm{G}_{2} / \mathrm{M}$ phase arrest of $\mathrm{K} 562$ and $\mathrm{K} 562 \mathrm{r}$ cells via reducing the activity of $\mathrm{G} 2 / \mathrm{M}$ phase transition-related proteins Cyclin B1/CDC2 complex. LW-213 treatment induced apoptosis of K562 and K562r cells via inhibiting the expression of CDK9 through lysosome degradation, thus leading to the suppression of RNAPII phosphorylation, down-regulation of a short-lived anti-apoptic protein $\mathrm{MCL}-1$. The lysosome inhibitor, $\mathrm{NH}_{4} \mathrm{Cl}$, could reverse the anti-CML effects of $\mathrm{LW}-213$ including CDK9 degradation and apoptosis. LW-213 treatment also degraded the downstream proteins of BCR-ABL1, such as oncoproteins AKT, STAT3/5 in CML cells, which was blocked by $\mathrm{NH}_{4} \mathrm{Cl}$. In primary $\mathrm{CML}$ cells and $\mathrm{CD} 34^{+}$stem cells, $\mathrm{LW}-213$ maintained its pro-apoptotic activity. In a $\mathrm{K} 562$ cells-bearing mice model, administration of LW-213 $(2.5,5.0 \mathrm{mg} / \mathrm{kg}$, ip, every other day for 4 weeks) dose-dependently prolonged the survival duration, and significantly suppressed huCD45 ${ }^{+}$cell infiltration and expression of MCL- 1 in spleens. Taken together, our results demonstrate that $\mathrm{LW}-213$ may be an efficient agent for CML treatment.

Keywords: chronic myeloid leukemia; LW-213; G2/M phase arrest; lysosome-dependent apoptosis; CDK9; MCL-1

Acta Pharmacologica Sinica (2020) 41:249-259; https://doi.org/10.1038/s41401-019-0270-4

\section{INTRODUCTION}

Chronic myeloid leukemia (CML) affects approximately one individual per 100,000 people per year with a slight male preponderance and accounts for $15 \%$ of all new cases of leukemia [1]. The leukemic cells proliferate in an uncontrolled manner with the reciprocal translocation $\mathrm{t}(9 ; 22)$ (q34;q11), which results in the formation of the $b c r-a b /$ oncogene [2]. Constitutive expression of BCR-ABL1 transforms hematopoietic stem cells (HSCs) into CML stem cells that self-renew, proliferate and differentiate to give rise to myeloproliferative diseases [3]. BCR-ABL1 exhibits constitutive tyrosine kinase activity, and many proproliferation signaling molecules, such as RAS/RAF/MAP kinases, phosphoinositide 3kinase (PI3-kinase), and signal transducer and activator of transcription 5 (STAT5), can be activated by BCR-ABL1 [2]. BCRABL1 also activates STAT3 via the JAK and MEK pathways [4]. The median survival of CML patients was 5-7 years before the tyrosine kinase inhibitors (TKIs) were used in the clinic [1]. Although TKIs achieved an excellent curative effect, CML stem cells do not respond to TKIs and persist in all patients who undergo long-term therapy. The presence of these cells is associated with poor prognosis, acquisition of TKI resistance, relapse, and disease progression [3].
LW-213, a newly synthesized flavonoid, is the derivative of wogonin. Previous studies suggested that wogonin and its structurally related natural flavones, such as apigenin, chrysin and luteolin, are inhibitors of cyclin-dependent kinase 9 (CDK9) [5]. CDK9 is an important member of the CDK family and affects transcription. CDK9 can phosphorylate S2 residues in the CTD (C-terminal domain) of RNAPII (RNA polymerase II), which is required for transcript elongation [6]. Inhibition of CDK9 activity prevents the transcription of RNAPII, which leads to the downregulation of myeloid cell leukemia 1 (MCL-1), a short-lived antiapoptotic protein. Therefore, apoptosis can be induced [7]. MCL-1 is an antiapoptotic member of the $\mathrm{BCL}-2$ family. It differs from other members of the BCL-2 family by its short half-life due to the degradation through the proteasome pathway [8]. MCL-1 has been considered the most relevant therapeutic target in multiple types of cancer and a relevant therapeutic target in acute and chronic lymphoid malignancies. Previous studies showed that inhibition of MCL-1 expression with RNA interference is sufficient to promote mitochondrial membrane depolarization and apoptosis in leukemic cells [9]. In CML cells, BCRABL1 promotes the expression of MCL-1, and MCL-1 is expressed in primary CML cells in a constitutive manner at the mRNA and protein levels [2].

\footnotetext{
${ }^{1}$ State Key Laboratory of Natural Medicines, Jiangsu Key Laboratory of Carcinogenesis and Intervention, China Pharmaceutical University, Nanjing 210009, China Correspondence: Qing-long Guo (anticancer_drug@163.com) or Hui Hui (moyehh@163.com)

These authors contributed equally: Xiao Liu, Po Hu
}

Received: 13 March 2019 Accepted: 8 June 2019

Published online: 17 July 2019 
LW-213 has been suggested to possess antitumor effects by inducing G2/M arrest in breast cancer [10]. We also proved that LW-213 could inhibit the proliferation of CML cells by inducing G2/M phase arrest as well as noteworthy apoptosis effects. LW213 inhibited the activity of CDK9, decreased the expression of MCL-1 and interfered with the downstream proteins of BCR$A B L 1$ in both CML cell lines and primary cells. In this article, a new mechanism by which LW-213 exerts its anti-CML effects was investigated.

\section{MATERIALS AND METHODS}

Compounds and reagents

LW-213 (99\% purity, MW $=445.52)$ was synthesized and provided by Prof. Zhi-yu Li in our lab. For in vitro experiments, LW-213 was dissolved in dimethyl sulfoxide (DMSO, Sigma-Aldrich, St. Louis, MO, USA) as a stock solution at a concentration of $0.02 \mathrm{M}$. The stock solution was stored at $-20^{\circ} \mathrm{C}$ and freshly diluted to an indicated concentration with RPMI-1640 medium (GIBCO, Carlsbad, CA, USA). For in vivo experiments, LW-213 was prepared for intraperitoneal injection by Dr. Xue Ke from College of Pharmacy, China Pharmaceutical University. Primary CDK9 antibody was obtained from Cell Signaling Technology (Danvers, MA). Primary antibodies for Cyclin B1, CDC2, p-CDC2 (Y15), $\beta$-tubulin, MCL-1, pCDK9 (Thr186), AKT, p-AKT (Ser473), $\beta$-actin, BCL-2, STAT5, STAT3, p-STAT5 (Y694), p-RNAPII-S2, p-RNAPII-S5, ABL1, LC3, P62/SQSTM1, caspase 3, and caspase 9 were obtained from ABclonal Technology (Wuhan, China). IRDyeTM 800-conjugated secondary antibodies were purchased from Rockland (Philadelphia, PA, USA). MG-132 was purchased from KeyGENE BioTECH (Jiangsu, China). MG-132 powder was dissolved in DMSO and stored at $-20^{\circ} \mathrm{C}$. 3MA (Sigma-Aldrich, St. Louis, MO) was dissolved in $\mathrm{ddH}_{2} \mathrm{O}$ and stored at $-20^{\circ} \mathrm{C}$.

\section{Cell culture}

The human CML cell line K562 and imatinib-resistant K562 cells (K562r) were purchased from the Cell Bank of Shanghai Institute of Biochemistry \& Cell Biology. Primary leukemia cells from newly diagnosed CML patients at the First Affiliated Hospital of Nanjing Medical University, Nanjing, China, who did not receive therapy were collected using lymphocyte-monocyte separation medium (Jingmei, Nanjing, China). Signed informed consent was obtained from each patient. The cell lines and primary CML cells were cultured in RPMI-1640 medium supplemented with $10 \%$ fetal bovine serum (FBS) (GIBCO, Carlsbad, USA), $100 \mathrm{U} / \mathrm{mL}$ benzylpenicillin and $100 \mu \mathrm{g} / \mathrm{mL}$ streptomycin at $37^{\circ} \mathrm{C}$ in a humidified environment with $5 \% \mathrm{CO}_{2}$.

\section{Animal models}

Female NOD/SCID nude mice (5-6 weeks old, weighing 18-22 g) (Slaccas Shanghai Laboratory Animal Co., Ltd, Shanghai, China) were sublethally irradiated $(1.8 \mathrm{~Gy})$ and engrafted with $\mathrm{K} 562$ cells $\left(5 \times 10^{6}\right)$ via tail vein injection $24 \mathrm{~h}$ following radiation treatment. After 7 days, animals were randomly assigned to the control group, the low dose LW-213 group, and the high dose LW-213 group ( $n=10$ per group). The animals were intraperitoneally (i.p.) injected with $2.5 \mathrm{mg} / \mathrm{kg} \mathrm{LW}-213$ in the low dose LW-213 group and $5 \mathrm{mg} / \mathrm{kg}$ in the high dose LW-213 group every other day for 4 weeks. The animals in the control group received i.p. injection of physiological saline solution. Finally, the cells from spleen tissue were collected for immunofluorescence detection after labeling with human CD45-PE (huCD45-PE, Miltenyi Biotec, Auburn, CA, USA) and MCL- 1 antibody. The images were captured with a confocal microscope at $\times 1000$ magnification (FluoView FV1000, Olympus, Tokyo, Japan). The number of surviving mice was counted. The animal study was carried out according to the regulations of the China Food and Drug Administration (CFDA) on
Animal Care. Animals were maintained in an air-conditioned and pathogen-free environment $\left(23 \pm 2{ }^{\circ} \mathrm{C}, 55 \% \pm 5 \%\right.$ humidity) under controlled lighting ( $12 \mathrm{~h}$ light/day) and supplied with standard laboratory food and water ad libitum throughout the experimental period.

\section{Cell proliferation assays}

Cell growth was assessed using the trypan blue exclusion method by manual cell counting using a hemocytometer (Qiujing, Shanghai, China) [11]. The results are reported as the cell number. MTT assays were performed to evaluate the growth inhibitory effect of the drug treatments [11]. The concentration that caused $50 \%$ inhibition of cell viability $\left(I_{50}\right)$ values was calculated with GraphPad software.

\section{Cell cycle detection}

The cell cycle distribution was analyzed by propidium iodide (PI) staining and quantified using a BD FACSCalibur flow cytometer (Becton, Dickinson, San Jose, CA). The cells were collected and then fixed with $70 \%$ ethanol for $2 \mathrm{~h}$ at $4{ }^{\circ} \mathrm{C}$. After fixation, the cells were washed with PBS buffer and stained with PI for $30 \mathrm{~min}$. The fluorescence was detected by flow cytometry. The percentage of cells in G0/G1, S, and G2/M phases of the cell cycle was determined by the PI fluorescence signal peak versus the integral and quantitated with FlowJo software.

\section{Apoptosis detection}

An Annexin V/PI staining assay was used to detect apoptosis of cells after LW-213 treatment. The cells were collected and washed with PBS buffer. The cells were resuspended in $100 \mu \mathrm{L}$ of binding buffer and stained with $5 \mu \mathrm{L}$ of Annexin $V$ and $5 \mu \mathrm{L}$ of PI for $10 \mathrm{~min}$ (The Annexin V/PI apoptosis kit was purchased from Vazyme Biotech, Nanjing, China). The fluorescence was detected by flow cytometry on a Becton-Dickinson FACSCalibur, and the data analysis was performed with FlowJo software and BD C6 flow cytometry software.

Western blot assays

After LW-213 treatment for the indicated time, total protein was extracted from cells with RIPA Lysis and Extraction Buffer (Thermo Fisher Scientific, USA). The lysates were centrifuged at $12000 \times g$ for $15 \mathrm{~min}$ at $4{ }^{\circ} \mathrm{C}$. The concentration of proteins was determined with a BCA Protein Assay Kit (Thermo Fisher Scientific, USA). Then, equal amounts of protein were separated with $8 \%-12 \%$ SDS-PAGE and transferred to PVDF membranes (Millipore, Boston, MA, USA). After the membranes were blocked with $1 \%$ BSA for $2 \mathrm{~h}$ at room temperature, they were incubated with primary antibodies overnight at $4{ }^{\circ} \mathrm{C}$. After washes with PBST, the membranes were incubated with secondary antibodies for $1 \mathrm{~h}$ at room temperature. Protein band detection was performed with the Odyssey Infrared Imaging System (LI-COR Inc., Lincoln, NE, USA).

Magnetic-activated cell sorting (MACS)

Primary CML cells or the cells collected from umbilical cord blood were thoroughly washed, and the cell counts were set at $2 \times 10^{7}$. The cells were resuspended in $250 \mu \mathrm{L}$ of $1 \times \mathrm{BD} \mathrm{IMag}^{\mathrm{TM}}$ buffer. The CD34 antibody (Miltenyi Biotec, USA) was added at $4{ }^{\circ} \mathrm{C}$ for $15 \mathrm{~min}$, and the cells were washed twice with $1 \times \mathrm{BD}$ IMag $^{\mathrm{TM}}$ buffer. Then, $50 \mu \mathrm{L}$ of magnetic bead solution was added to $100 \mu \mathrm{L}$ of the cell suspension and incubated for $30 \mathrm{~min}$ at room temperature. The columns were set on a magnet. The column was primed by adding $500 \mu \mathrm{L}$ of wash buffer and letting the solution drip through completely. The cell suspension was then added to the column in a magnetic field for $6 \sim 8 \mathrm{~min}$ and the supernatant was removed. Next, buffer was added to wash the cells, and the column was placed on the magnet for $2 \sim 4 \mathrm{~min}$. The washing process was repeated two times, and the 
bound cells were incubated in medium or buffer for treatment or detection.

\section{CFSE proliferation assay}

The CD34 ${ }^{+}$cells isolated by MACS were centrifuged at $1000 \mathrm{r} / \mathrm{min}$ for $5 \mathrm{~min}$ and resuspended in serum-free medium to $1 \mathrm{~mL}$. The CFSE stock solution was added to the cell suspension (1:1000). The cells were incubated for $20 \mathrm{~min}$ at $37^{\circ} \mathrm{C}$ in the dark. The medium was replaced after incubation, and the cells were treated with different concentrations of LW-213. Fluorescence was detected by flow cytometry on a Becton-Dickinson FACSCalibur.

\section{Immunofluorescence}

The paraffin sections of spleens on cover slips were fixed in icecold methanol for $15 \mathrm{~min}$ and permeabilized in $0.15 \%(\mathrm{v} / \mathrm{v})$ Triton X-100 for $20 \mathrm{~min}$. After blocking with 3\% BSA for $1 \mathrm{~h}$ at room temperature, the cells were incubated with primary antiMCL-1 antibody overnight at $4{ }^{\circ} \mathrm{C}$, followed by incubation with Alexa Fluor 488 goat anti-rabbit lgG antibody (1:500) for $1 \mathrm{~h}$. The huCD45-PE antibody was incubated with the cells for $50 \mathrm{~min}$ at $37^{\circ} \mathrm{C}$, and DAPI (Beyotime Biotechnology, Shanghai, China) was added to the cells at room temperature for $15 \mathrm{~min}$ before the sections were sealed. For the cell lines, K562 and K562 $r$ cells treated with LW-213 were seeded on the cover slips. After fixation and blocking, the cells were incubated with primary anti- $\beta$-tubulin antibody overnight at $4{ }^{\circ} \mathrm{C}$, followed by incubation with Alexa Fluor 488 goat anti-rabbit IgG antibody. The cells were then stained with PI for $30 \mathrm{~min}$ before the samples were sealed. The cells were observed on a confocal laser scanning microscope (FluoView FV1000, Olympus, Tokyo, Japan).

Cell transfection with CDK9 plasmid

CDK9 plasmid $(3 \mu \mathrm{g})$ was added to $200 \mu \mathrm{L}$ of serum-free medium without antibiotic and incubated at room temperature for $5 \mathrm{~min}$. Next, $8 \mu \mathrm{L}$ of Lipofectamine 2000 reagent (Life Technologies, Grand Island, NY, USA) was added to serum-free medium without antibiotic to final volume of $200 \mu \mathrm{L}$ and incubated at room temperature for $5 \mathrm{~min}$. The two solutions above were mixed, incubated at room temperature for $20 \mathrm{~min}$ and then added to 2 $\mathrm{mL}$ of cell suspension. The cells were incubated at $4{ }^{\circ} \mathrm{C}$ for $8 \mathrm{~h}$, and the transfection medium was replaced with complete medium, which was incubated with the cells for $40 \mathrm{~h}$.

Statistical analysis

All data are expressed as the mean \pm S.E.M. from at least three independent experiments performed in a parallel manner. Statistical analysis of multiple group comparisons was performed by one-way analysis of variance (ANOVA) followed by the Bonferroni post hoc test. Comparisons between two groups were analyzed using two-tailed Student's $t$-tests. A $P$-value $<0.05$ was considered statistically significant.

\section{RESULTS}

LW-213 decreases the viability of CML cell lines in vitro

The chemical structure of LW-213 is shown in Fig. 1a. We first assessed the cytotoxic effects of LW-213 using the MTT assay. The CML cell lines K562 and K562r were incubated with various concentrations of LW-213 for 24, 48, 72 and $96 \mathrm{~h}$. Cell viability decreased in a concentration- and time-dependent manner (Fig. 1b-d). We also determined the antiproliferative effects of LW-213 on $\mathrm{K} 562$ and $\mathrm{K} 562 \mathrm{r}$ cells by the trypan blue dye exclusion assay (Fig. 1e, f). The results showed that LW-213 inhibited the growth of CML cell lines. Because inhibition of cell viability may result either from cell cycle arrest or cell death [12], we then investigated both in subsequent experiments.
LW-213 blocks CML cell cycle progression at G2/M phase

The effects of LW-213 on cell cycle progression were evaluated by PI staining analysis. CML cell lines treated with $0,5,10$, and $15 \mu \mathrm{M}$ LW-213 showed an accumulation of cells in G2/M phase at 12 and $24 \mathrm{~h}$ (Fig. 2a-c). Comparison with the untreated cells revealed an apparent concentration- and time-dependent increase in the percentage of $\mathrm{G} 2 / \mathrm{M}$ cells. The immunofluorescence assays showed that the number of cells in mitosis increased by $5.03 \%$ and $3.91 \%$ in $\mathrm{K} 562$ and $\mathrm{K} 562 \mathrm{r}$ cells, respectively, suggesting that G2 phase arrest was induced by LW-213 (Fig. 2d, e). To further investigate the pathways affected by LW-213, we examined the expression levels of G2/M phase-transition-related proteins under the same conditions (Fig. 2f, g). Progression through G2/M requires activated Cyclin B1/CDC2 complexes [10]. After treatment with LW-213, a decrease in Cyclin B1 expression was observed. In K562 cells ( $24 \mathrm{~h}$ ) and K562r cells, LW-213 increased the level of $p$ $\mathrm{CDC} 2$, an inactivated form of CDC2 (Fig. 2f). This result indicated that the activity reduction of the Cyclin B1/CDC2 complex resulted in $\mathrm{G} 2 / \mathrm{M}$ arrest.

LW-213 induces lysosome-dependent apoptosis via the CDK9RNAPII-MCL-1 axis and promotes protein degradation of BCR-ABL1 downstream

To evaluate whether the antiproliferation effects of LW-213 were associated with apoptosis, $\mathrm{K} 562$ and $\mathrm{K} 562 \mathrm{r}$ cells were treated with $0,5,10$, and $15 \mu \mathrm{M}$ of LW-213, and statistically profound increase in apoptotic rates was detected by flow cytometric analysis after 12 and $24 \mathrm{~h}$ of treatment (Annexin V and PI double-positive, Fig. 3a-c). Apoptosis was further investigated by Western blot, and concentration-dependent cleavage of caspase 3/9 was revealed (Fig. 4a). Furthermore, the apoptosis induced by LW-213 could be reversed by the lysosome inhibitor $\mathrm{NH}_{4} \mathrm{Cl}(10 \mathrm{mM})$ (Fig. 3d, e), indicating that this type of apoptosis might be lysosomedependent.

Previous studies have demonstrated that wogonin and other structurally related natural flavones are inhibitors of CDK9 [5]. To investigate the molecular mechanisms by which LW-213 induces apoptosis in cancer cells, we first investigated the effects of LW-213 on CDK9, and the results revealed that LW-213 decreased the levels of both phosphorylated CDK9 and total CDK9 (Fig. 4b). Next, we analyzed the expression of BCL-2 family proteins. The cellular levels of $\mathrm{MCL}-1$ protein decreased significantly after treatment with LW-213 (Fig. 4a). MCL-1 is an antiapoptosis protein and has been considered to be the most relevant therapeutic target [13]. CDK9 plays a major role in the regulation of transcription and promotes the phosphorylation of the carboxyl-terminal domain of RNA polymerase II (RNAPII) at $\mathrm{Ser}^{2}$ (S2), which is required for transcript elongation. The activation of RNAPII contributes to the transcription of MCL-1 mRNA and its subsequent translation [5]. We then determined the phosphorylation of RNAPII at S2. Western blot analysis of CML cell lines treated with different concentrations of LW-213 showed that S2 phosphorylation and S5 phosphorylation were diminished in a concentration-dependent manner after $12 \mathrm{~h}$ of treatment (Fig. 4b).

We also determined the effects of $\mathrm{NH}_{4} \mathrm{Cl}$ on the expression of CDK9 after treatment with LW-213. $\mathrm{NH}_{4} \mathrm{Cl}$ could significantly prevent LW-213-induced degradation of CDK9 (Fig. 4c-e). This demonstrated that degradation of CDK9 proteins is involved in LW-213-induced apoptosis. Then, K562 cells were transfected with the CDK9 plasmid. The overexpression of CDK9 rescued the reduction of MCL-1 expression induced by treatment with LW-213 (Fig. 4f, g), and the cells were rescued from LW-213-induced apoptosis (Fig. 4h, i). The ubiquitin-proteasome pathway is a major intracellular system for protein degradation [14]. However, the ubiquitin-proteasome pathway might not be involved in LW-213induced apoptosis because of the inability of MG-132 to rescue cells from death (Fig. 3f, g). 
<smiles>CN(C)CCCOc1c(OCc2ccccc2)cc(O)c2c1OC(c1ccccc1)CC2=O</smiles>

The $I_{50}$ values of $L W-213$ against $C M L$ cell lines.

\begin{tabular}{ccc}
\hline \multirow{2}{*}{ Time $(h)$} & \multicolumn{2}{c}{ Cell lines } \\
\cline { 2 - 3 } & K562 & K562r \\
\hline 24 & $28.73 \pm 3.44$ & $35.43 \pm 4.98$ \\
48 & $8.63 \pm 2.45$ & $9.25 \pm 3.01$ \\
72 & $5.72 \pm 2.19$ & $4.36 \pm 1.77$ \\
96 & $4.70 \pm 1.86$ & $3.83 \pm 1.65$ \\
\hline
\end{tabular}

C

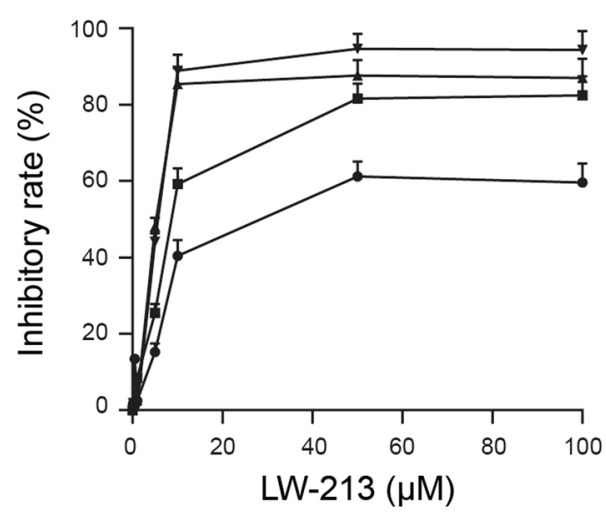

e

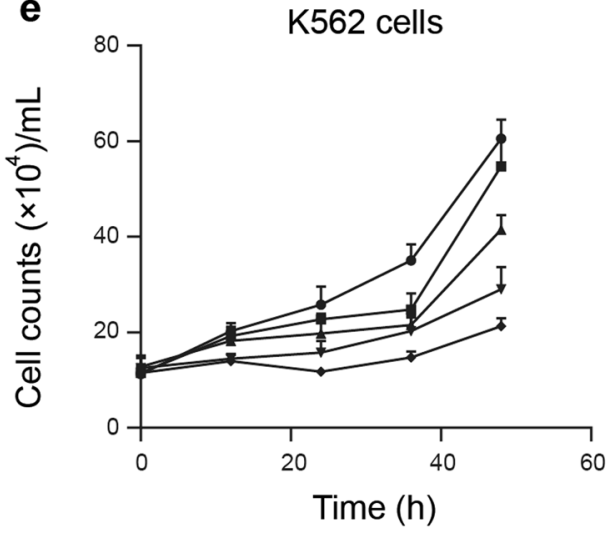

d K562r cells

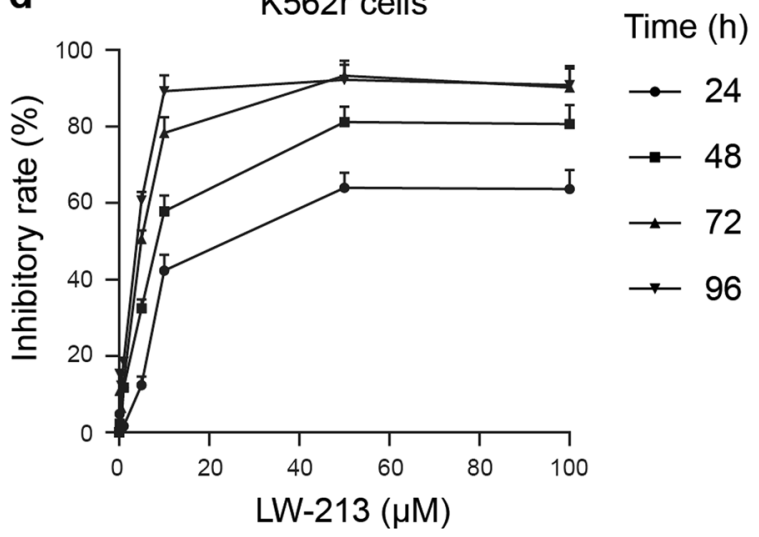

f

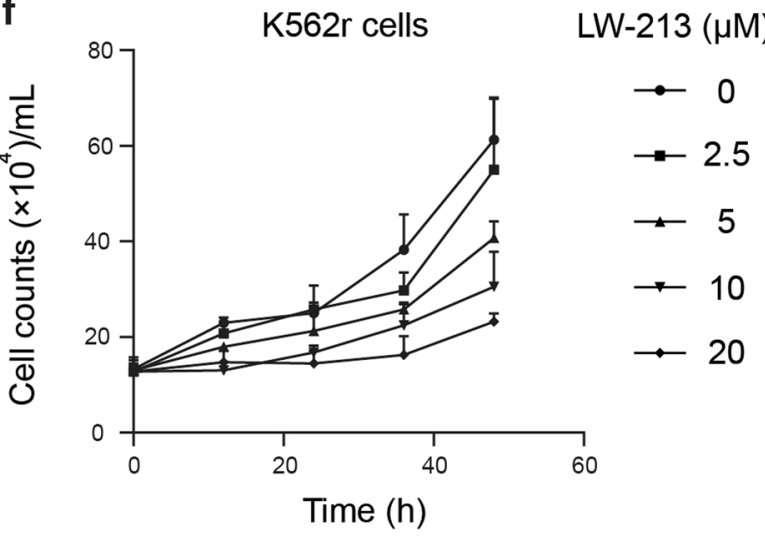

Fig. 1 Growth inhibition effects of LW-213 on CML cells in vitro. a The molecular structure of $L W-213\left(C_{27} \mathrm{H}_{27} \mathrm{NO} \mathrm{O}_{5}, \mathrm{MW}=445.5\right)$. b The IC 50 values (mean \pm S.E.M.) of LW-213 against K562 and K562r cells based on MTT assays. C, d The inhibitory effects of LW-213 on K562 and K562r cells were detected by the MTT assay. The cells were treated with increasing concentrations of LW-213 at 24, 48, 72, and $96 \mathrm{~h}$. Each group consisted of three parallel wells, and at least three independent experiments were performed. e, $\mathbf{f}$ Cell growth was measured by the trypan blue exclusion assay. The cell growth curves represent the effects of different concentrations of LW-213 on K562 and K562r cells after treatment for $12,24,36$, and $48 \mathrm{~h}$

LW-213 induces the expression reduction of proteins downstream of BCR-ABL1

We determined whether LW-213-induced lysosome degradation could affect oncoproteins in CML cells. AKT, STAT3 and STAT5 protein expression was determined; decreases in the levels of these proteins were observed after LW-213 treatment, and the reduction could be reversed by $\mathrm{NH}_{4} \mathrm{Cl}$ (Fig. $5 \mathrm{a}$, b). Previous studies demonstrated that the activity of STAT5 contributes to the expression of MCL-1 [2]. PI3K/AKT and MEK/ERK/STAT3 also promote cell proliferation $[4,15]$. Deregulation of proteins in the cancer cell proliferation signal transduction pathway by LW-213 contributed to apoptosis and cell death. LW-213 treatment also resulted in the degradation of these proteins in primary CML cells (Fig. 5c).

LW-213 promotes apoptosis in CD34 ${ }^{+}$cells and primary CML cells Primary CML cells were isolated from CML patients. Samples \#1 \#4 were treated with $0 \sim 15 \mu \mathrm{M} \mathrm{LW}-213$, and an increase in the proportion of apoptotic cells was observed (Fig. 6a-d). LW-213 reduced the levels of $\mathrm{p}-\mathrm{CDK} 9, \mathrm{CDK} 9$, pro-caspase 3 and MCL-1 in primary CML cells from sample \#1 (Fig. 6e).

Although TKls targeting BCR-ABL1 achieve an excellent therapeutic effect, strong evidence shows that CML stem cells are resistant to TKIs [3]. The CML stem cells are not fully 
a
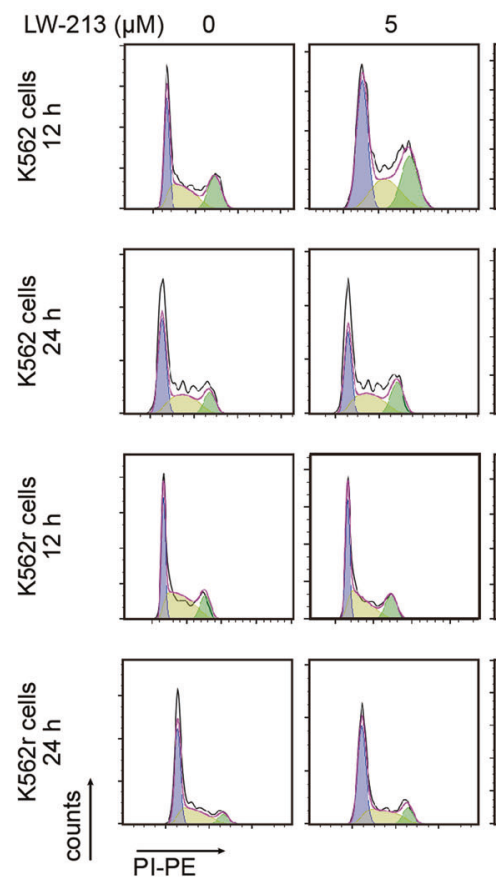

d
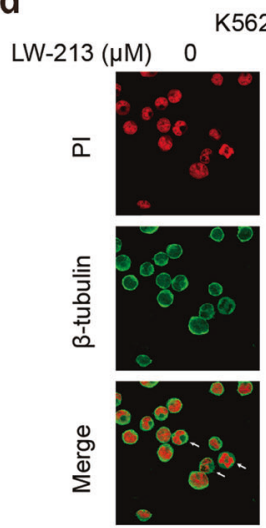

2 cells

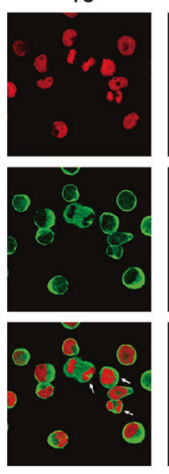

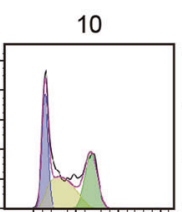
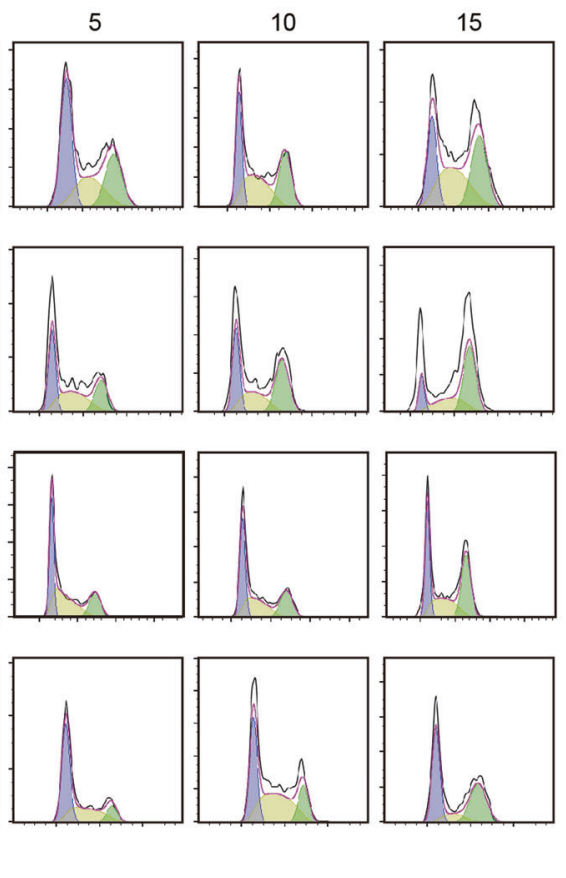

b

K562 cells

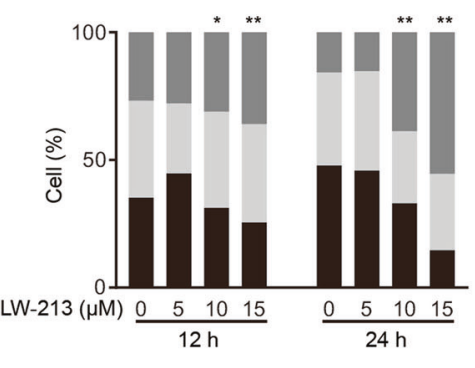

C

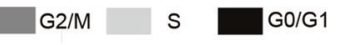

$\mathrm{K} 562 \mathrm{r}$ cells

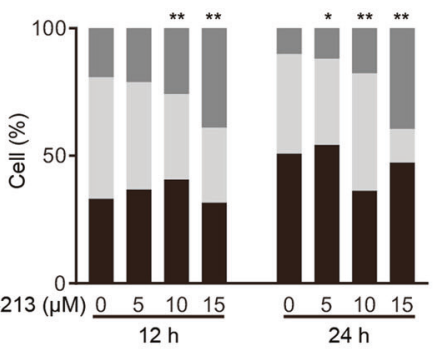

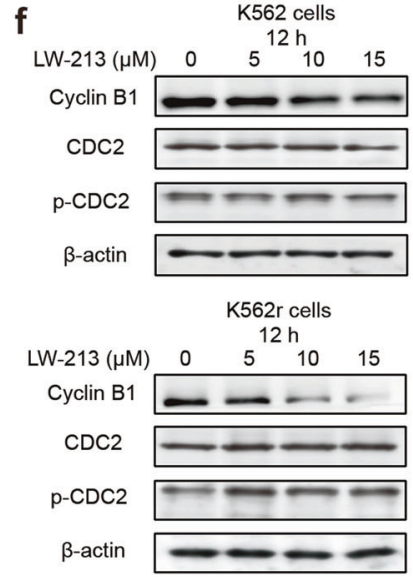
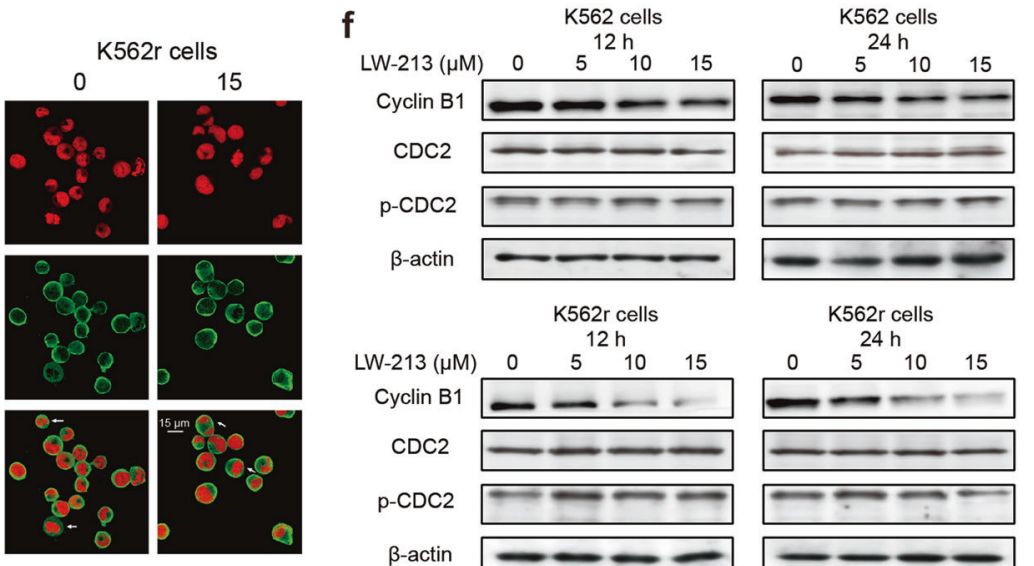

g
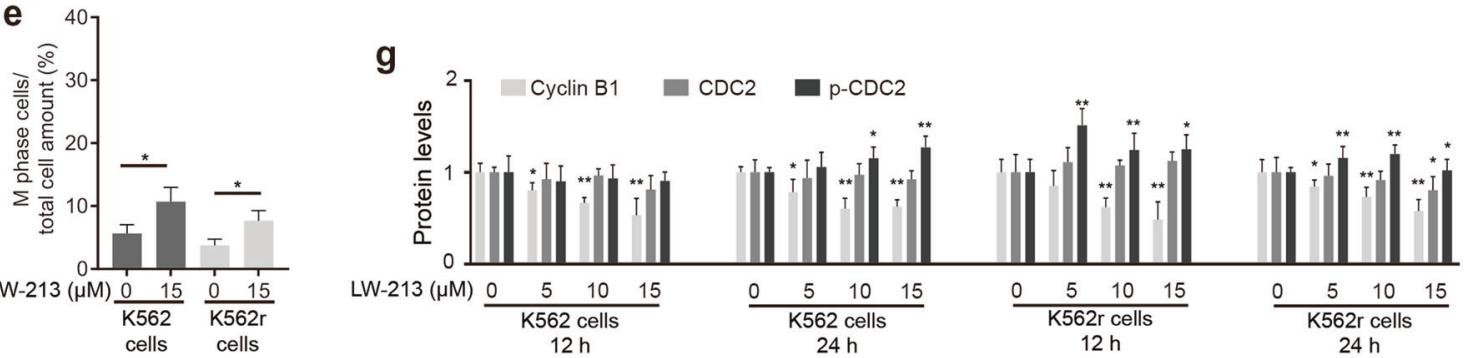

Fig. $2 \mathrm{LW}-213$ induced G2/M phase arrest in CML cell lines. a K562 and K562r cells were treated with the indicated concentrations of LW-213

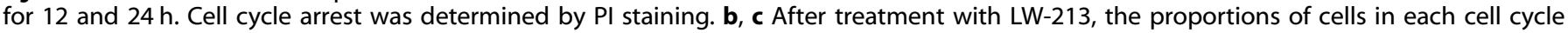
phase were summarized. Data represent the mean \pm S.E.M. from three independent experiments. Asterisks denote statistically significant differences compared with untreated cells ( ${ }^{*} P<0.05,{ }^{* *} P<0.01$ ). d, e After treatment with 0 and $15 \mu \mathrm{M}$ LW-213 for $24 \mathrm{~h}, \mathrm{~K} 562$ and $\mathrm{K} 562 \mathrm{r}$ cells

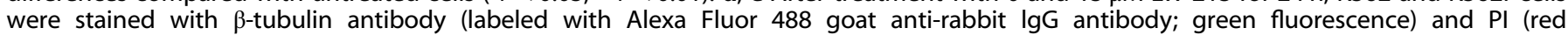
fluorescence). The number of cells in M phase was quantified in three experiments, with 200 cells per condition. Asterisks denote statistically significant differences compared with untreated cells ( $\left.{ }^{*} P<0.05\right)$. f, g Levels of Cyclin B1, CDC2 and $p-C D C 2$ in K562 and K562r cells were analyzed by Western blots after treatment with LW-213 for 12 and $24 \mathrm{~h}$, respectively. $\beta$-Actin was used as a loading control. The results are

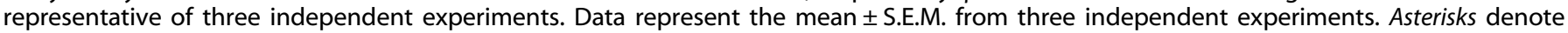
statistically significant differences compared with untreated cells $\left({ }^{*} P<0.05,{ }^{* *} P<0.01\right)$ 
LW-213 $(\mu \mathrm{M})$

$6 \mathrm{~h}$
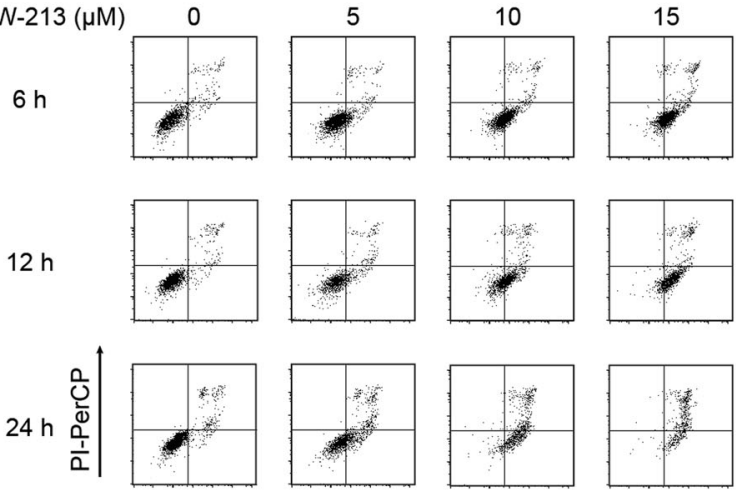

Annexin V-FITC

b

K562 cells

$$
\left.\begin{array}{ll} 
& 100 \\
\frac{0}{0} & 75 \\
\frac{00}{\bar{d}} & \\
0 & \\
\frac{01}{0} & 50 \\
\frac{0}{0} & \\
\frac{0}{0} & 25 \\
\frac{0}{4} &
\end{array}\right]
$$

$\mathrm{LW}-213(\mu \mathrm{M}) \quad 0$

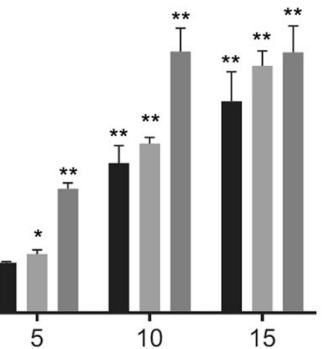

d
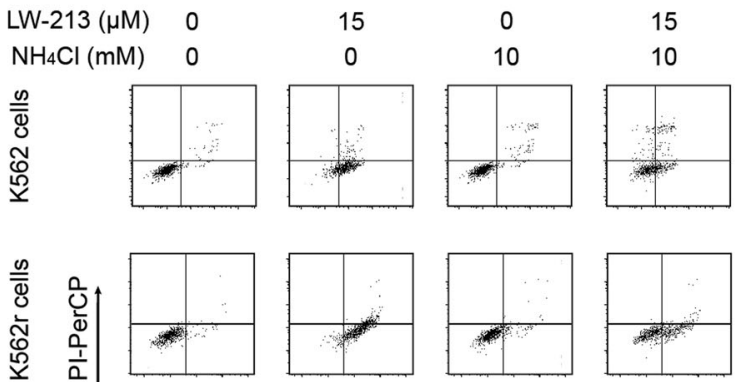

Annexin V-FITC
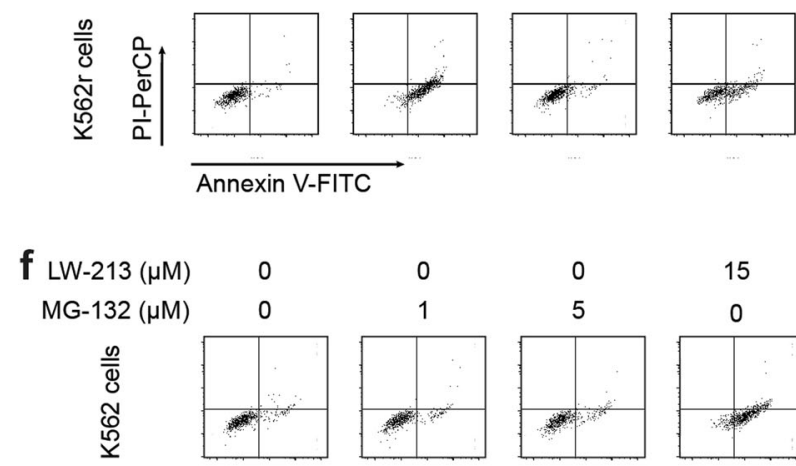

f LW-21
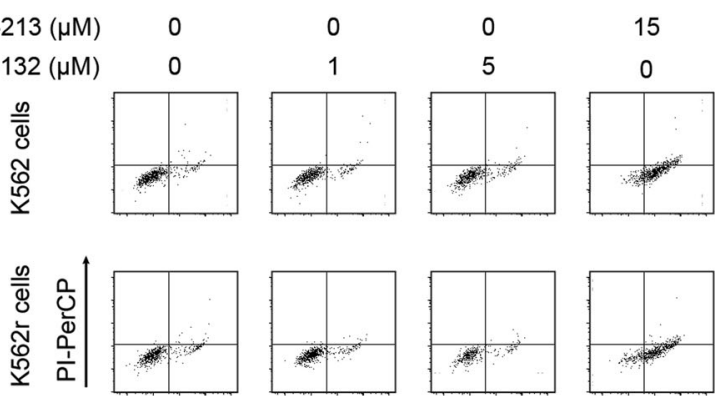

Annexin V-FITC

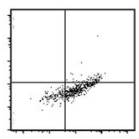

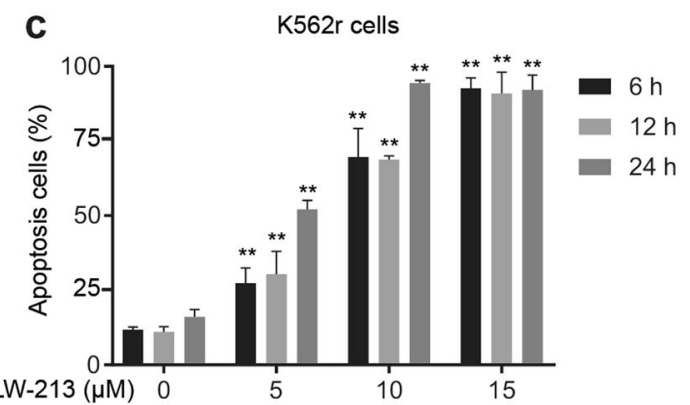
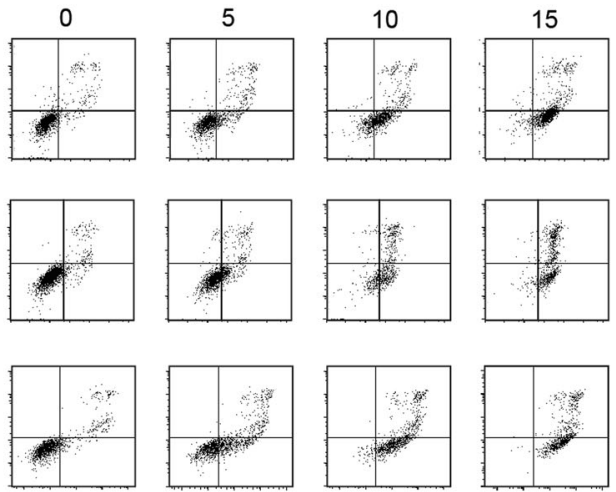

e

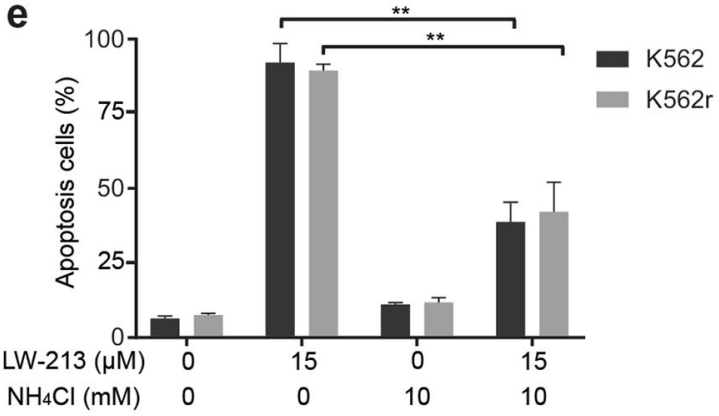

g
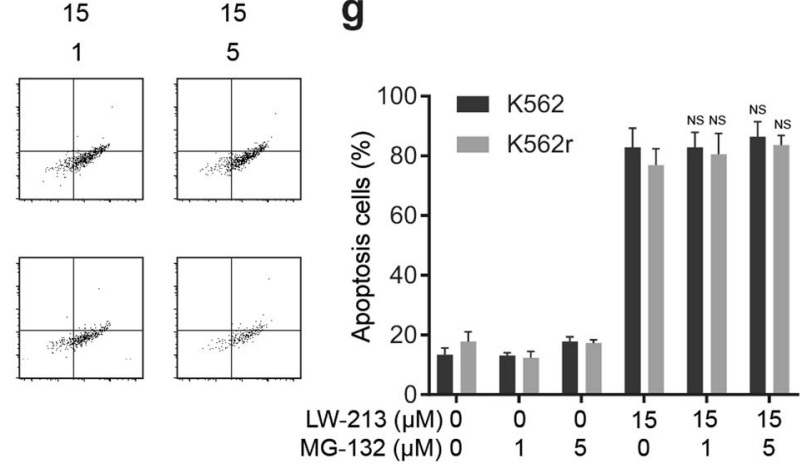

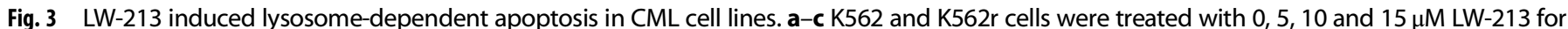

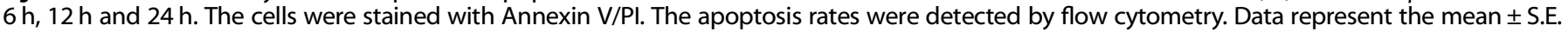

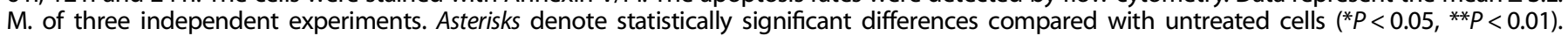

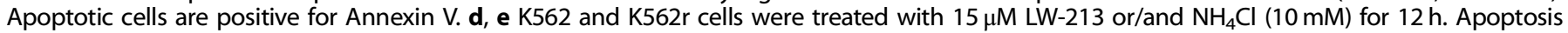

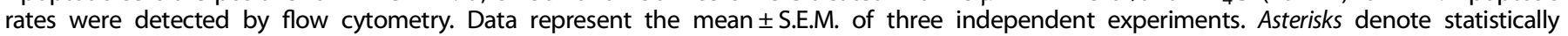

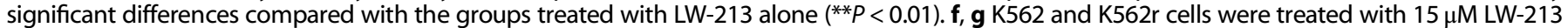

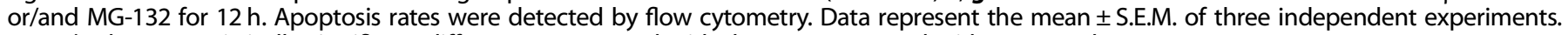
Asterisks denote statistically significant differences compared with the groups treated with LW-213 alone 


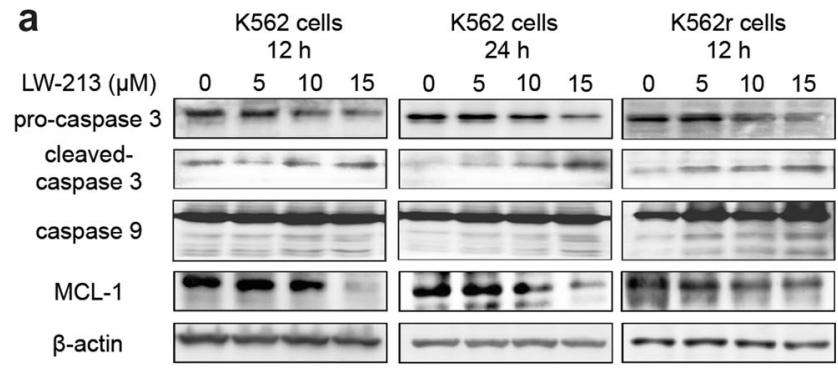

\section{K562r cells $24 \mathrm{~h}$}
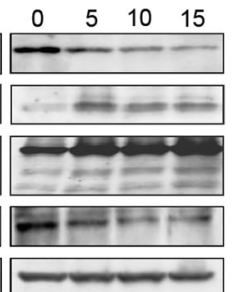

b K562 cells $12 \mathrm{~h}$

$\mathrm{K} 562 \mathrm{r}$ cells $12 \mathrm{~h}$ $\begin{array}{lllllllll}\mathrm{LW}-213(\mu \mathrm{M}) & 0 & 5 & 10 & 15 & 0 & 5 & 10 & 15\end{array}$ p-RNAPII-S5 p-RNAPII-S2 G ba bull baba bath p-CDK9 $---\infty-7$ CDK9 $-\infty-\infty-\infty$ $\beta$-actin $-\infty-\infty$
C

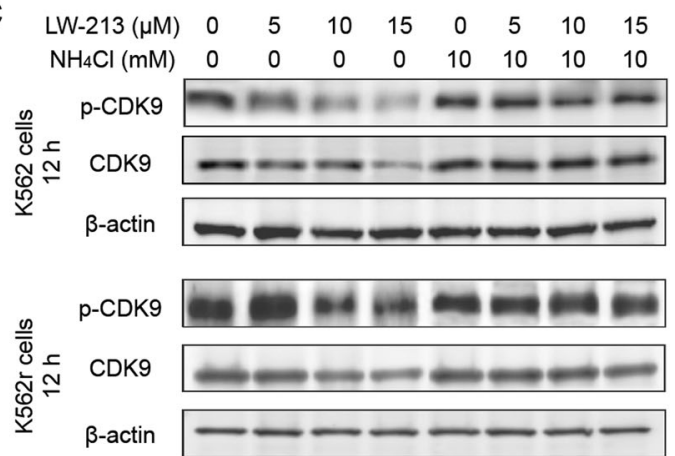

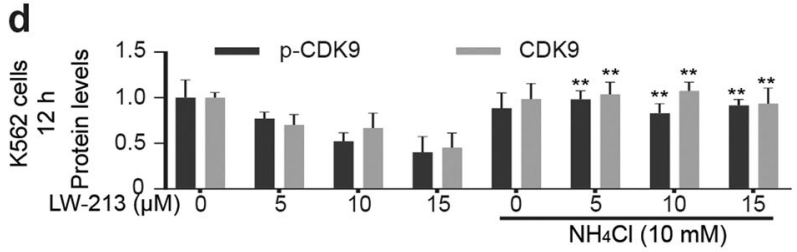

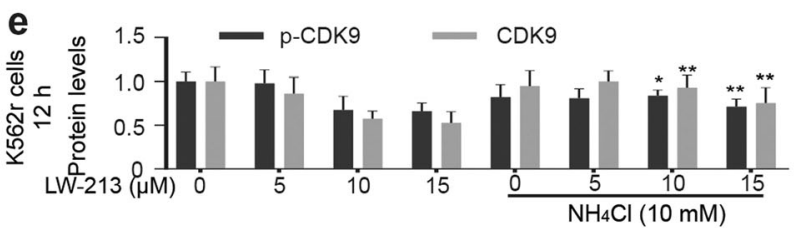

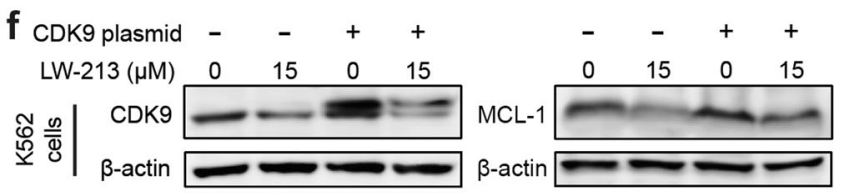

g

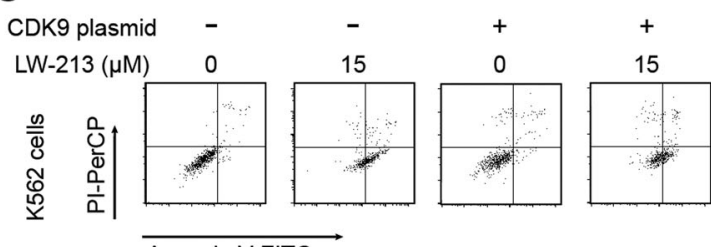

h

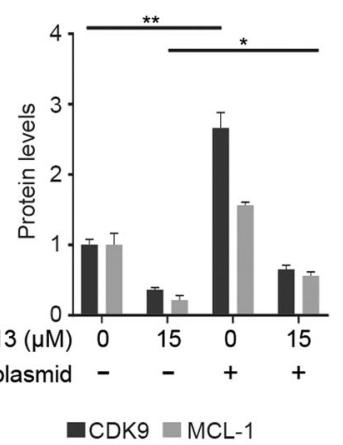

i

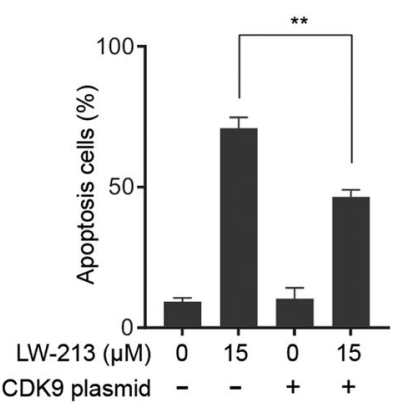

Fig. 4 Effects of LW-213 on the CDK9/RNAPII/MCL-1 signaling pathway in CML cells. a After treatment with $0,5,10$, and 15 $\mu M$ LW-213 for $12 \mathrm{~h}$ and $24 \mathrm{~h}$ in $\mathrm{K} 562$ and $\mathrm{K} 562 \mathrm{r}$ cells, the expression of caspase 3, caspase 9, and MCL- 1 was analyzed by Western blotting. $\beta$-Actin was used as a loading control. The results are representative of three independent experiments. b After treatment of K562 and K562r cells with 0, 5, 10, and $15 \mu \mathrm{M}$ LW-213 for $12 \mathrm{~h}$, the levels of p-RNAPII-S5, p-RNAPII-S2, CDK9 and p-CDK9 were analyzed by Western blotting. $\beta$-Actin was used as a loading control. The results are representative of three independent experiments. c-e K562 and K562 cells were treated with 0, 5, 10 , and 15 $\mu \mathrm{M} \mathrm{LW}-213$ or/and $\mathrm{NH}_{4} \mathrm{Cl}(10 \mathrm{mM})$ for $12 \mathrm{~h}$. Then, the levels of CDK9 and $\mathrm{p}$-CDK9 were analyzed by Western blotting. $\beta$-Actin was used as a loading control. The results are representative of three independent experiments. Data represent the mean \pm S.E.M. of three independent experiments. Asterisks denote statistically significant differences compared with the same groups without $\mathrm{NH}_{4} \mathrm{Cl}(10 \mathrm{mM})$ treatment $\left({ }^{*} P<0.05\right.$ and $\left.{ }^{* *} P<0.01\right)$. f, $\mathbf{h}$ K562 cells transfected with the CDK9 plasmid and control K562 cells were treated with 0 and $15 \mu \mathrm{M}$ LW-213 for $12 \mathrm{~h}$. The expression levels of CDK9 and MCL- 1 were determined by Western blotting. $\beta$-Actin was used as a loading control. Data represent the mean \pm S.E.M. of three independent experiments. Asterisks denote statistically significant differences between the two groups $\left({ }^{*} P<0.05\right.$ and ${ }^{* *} P<$ 0.01). g, i K562 cells transfected with the CDK9 plasmid and control K562 cells were treated with 0 and $15 \mu \mathrm{M}$ LW-213 for 12 h. Apoptosis was determined by Annexin V/PI staining. Data represent the mean \pm S.E.M. of three independent experiments. Asterisks denote statistically significant differences compared with untreated cells $\left({ }^{* *} P<0.01\right)$. Apoptotic cells are positive for Annexin $\mathrm{V}$

dependent on BCR-ABL1 for their survival, and this might be the reason for the insensitivity of CML stem cells to TKls [16]. These leukemia stem cell-like populations may have different immunophenotypes $\left(\mathrm{CD} 34^{+} \mathrm{CD} 38^{+}, \mathrm{CD} 34^{+} \mathrm{CD} 38^{-}, \mathrm{CD} 34^{-}\right) . \mathrm{CD} 34^{+} \mathrm{CD} 38^{-}$ stem cells seem to be the most resistant to therapy and the least immunogenic [17]. We isolated $\mathrm{CD}_{3} 4^{+}$hematopoietic progenitor cells from primary CML cells (sample \#1) by magnetic-activated cell sorting (MACS) (Fig. 6f, g). Following magnetic separation, $\mathrm{CD}_{4}{ }^{+}$cells were collected. After treatment with 0,10 , and $15 \mu \mathrm{M}$ of LW-213, cells treated with LW-215 had a higher percentage of cells with higher CFSE intensity than did untreated $\mathrm{CD} 34^{+}$cells (Fig. $6 \mathrm{~h}, \mathrm{i})$. These results indicated that LW-213 inhibited the proliferation of $\mathrm{CD}^{+} 4^{+}$cells. The high dose $(15 \mu \mathrm{M})$ of $\mathrm{LW}-213$ induced $58 \%$ apoptosis in $\mathrm{CD} 34^{+}$cells, thus supporting the ability of LW-213 to target CD34 $4^{+}$cells (Fig. 6j, k). The cytotoxic effects of LW-213 on normal CD34 ${ }^{+}$cells, which were isolated and purified from umbilical cord blood, were also determined. Cell viability decreased by $9.56 \%$ after treatment with $15 \mu \mathrm{M}$ LW-213, and the $\mathrm{IC}_{50}$ value was $26.73 \pm 1.47 \mu \mathrm{M}$ at $24 \mathrm{~h}$ (Fig. S1a).

LW-213 suppresses the proliferation of CML cells in vivo We next established a NOD/SCID mouse model engrafted with K562 cells via tail vein injection to examine the antileukemia effects of LW213 in vivo (Fig. 7a). Mice were equally distributed into three groups, 
a

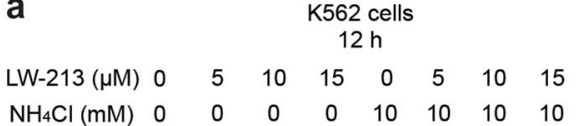

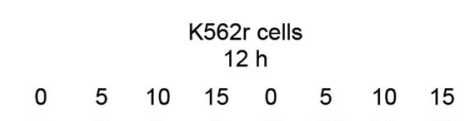

$\begin{array}{cccccccc}0 & 5 & 10 & 15 & 0 & 5 & 10 & 15 \\ 0 & 0 & 0 & 0 & 10 & 10 & 10 & 10\end{array}$

C

\#1 Primary CML cells $12 \mathrm{~h}$

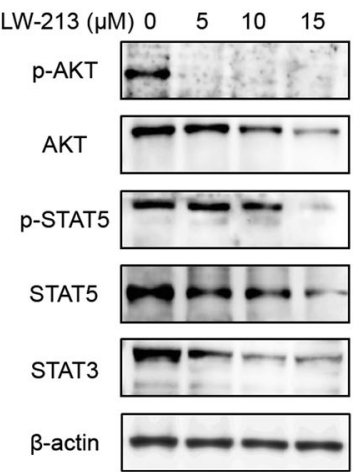

$\beta$-actin

b
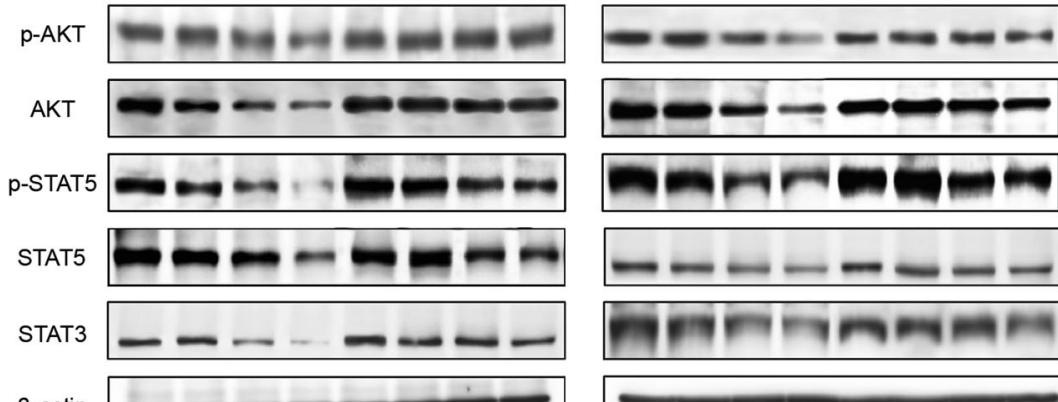

$\beta$-actin
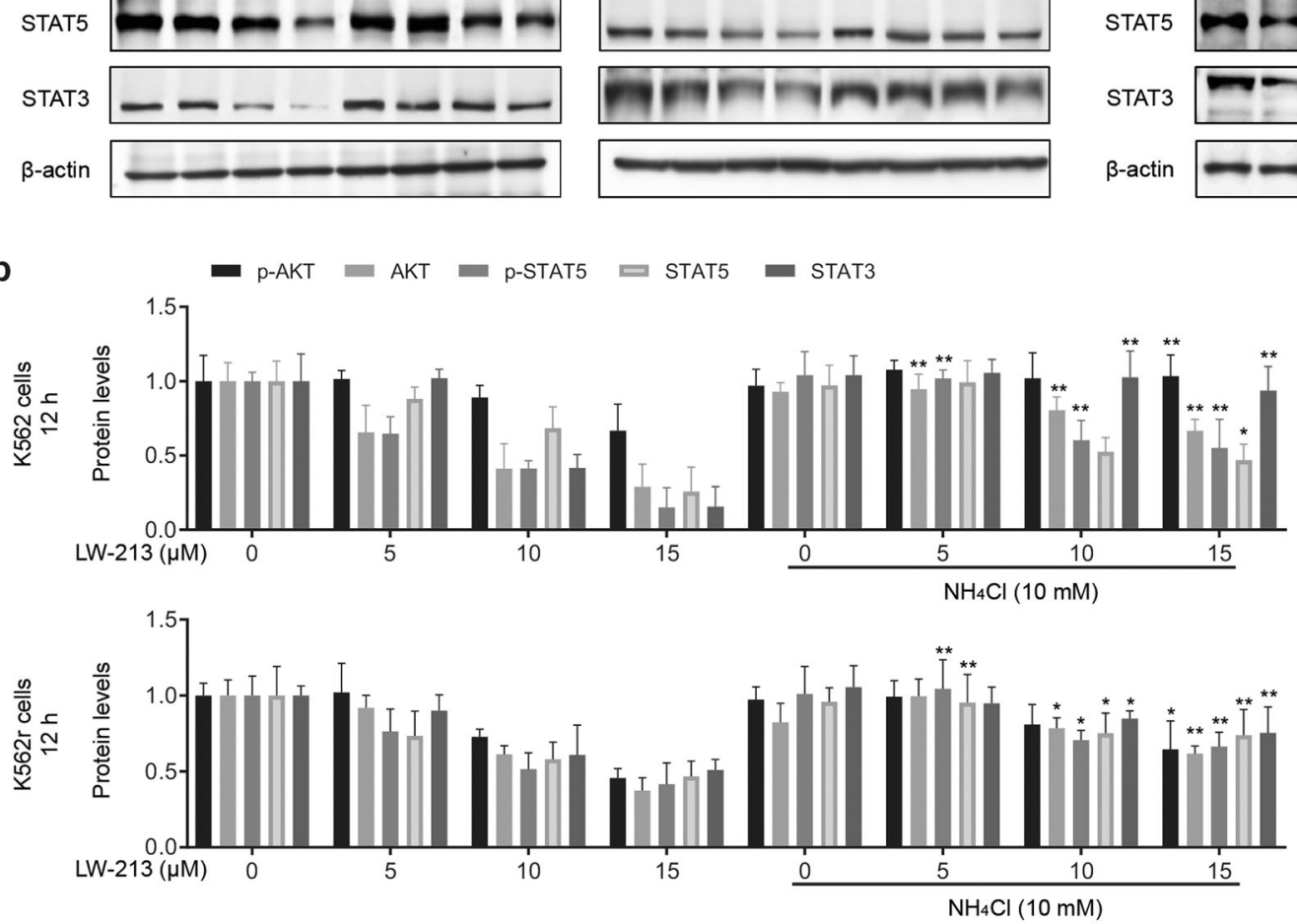

Fig. 5 Effects of LW-213 on the expression of proteins downstream of BCR-ABL1 in CML cells. a, b K562 and K562r cells were treated with 0, 5, 10 , and $15 \mu \mathrm{M} \mathrm{LW}-213$ or/and $\mathrm{NH}_{4} \mathrm{Cl}(10 \mathrm{mM})$ for $12 \mathrm{~h}$. Then, the levels of $\mathrm{p}$-AKT, AKT, p-STAT5, STAT5, and STAT3 were analyzed by Western blotting. $\beta$-Actin was used as a loading control. The results are representative of three independent experiments. Data represent the mean $\pm S$. E.M. of three independent experiments. Asterisks denote statistically significant differences compared with untreated cells $(* P<0.05, * * P<$ 0.01). c Levels of p-AKT, AKT, p-STAT5, STAT5, and STAT3 in primary cells (sample \#1) were analyzed by Western blotting after treatment with 0 , 5,10 , and $15 \mu \mathrm{M}$ of LW-213 for $12 \mathrm{~h}$

which received $2.5 \mathrm{mg} / \mathrm{kg} \mathrm{LW}-213,5 \mathrm{mg} / \mathrm{kg} \mathrm{LW}-213$ or saline. The results showed that mice in the control group expressed huCD45 in the spleen, and LW-213 significantly decreased the number of huCD45 $5^{+}$cells at both low and high doses. A significant reduction in MCL-1 expression in huCD45 ${ }^{+}$cells after treatment with LW-213 was observed, showing that LW-213 effectively blocks the activity of MCL-1 in vivo (Fig. 7c). LW-213 also extended the survival of K562 cell-bearing mice compared with mice in the control group. The median survival of the control mice injected with K562 cells was $15.5 \pm 19.9$ day. In the LW-213 groups, the median survival was $45.5 \pm 16.0$ and $48.5 \pm 19.2$ days at low and high doses, respectively (Fig. 7b). These results demonstrated that LW-213 suppresses the proliferation of CML cells in vivo.

\section{DISCUSSION}

Flavonoids are well known for their physiological antiinflammatory and antitumor activities [18]. To date, several flavonoids, such as wogonin, baicalein and oroxylin A, have been found to inhibit the proliferation of several human cancers $[11,19,20]$. LW-213, a newly synthesized flavonoid, could induce G2/M cell cycle arrest in human breast cancer cells via the
AKT/GSK3 $\beta / \beta$-catenin signaling pathway [10]. In this study, we examined the antitumor effects of LW-213 on CML cell lines and primary CML cells. Our studies were performed both in vitro and in vivo. LW-213 reduced cell viability in a concentration- and time-dependent manner in K562 and K562r cells. The LW-213 cytotoxic effects correlated with a significant induction of apoptosis and cleavage of caspase- 3 and -9 . In agreement with previous findings in other cancers, LW-213 induced cell cycle arrest at G2/M phase in CML cell lines, suggesting impairment in mechanisms involved in cell cycle progression and mitosis regulation.

Due to the remarkable apoptosis effects of LW-213, we then explored its mechanism. LW-213 is a derivative of wogonin. Wogonin and other structurally related natural flavones, such as apigenin, chrysin, and luteolin, are inhibitors of CDK9 and block phosphorylation of the carboxyl-terminal domain of RNA polymerase II at Ser2. This effect leads to reduced RNA synthesis and subsequent rapid downregulation of the short-lived antiapoptotic protein MCL-1, resulting in apoptosis induction in cancer cells [5]. MCL-1, an antiapoptotic protein in the BCL-2 family, has been found to be a therapeutic target due to its upregulation in numerous hematological malignancies and solid tumors and acts 
a
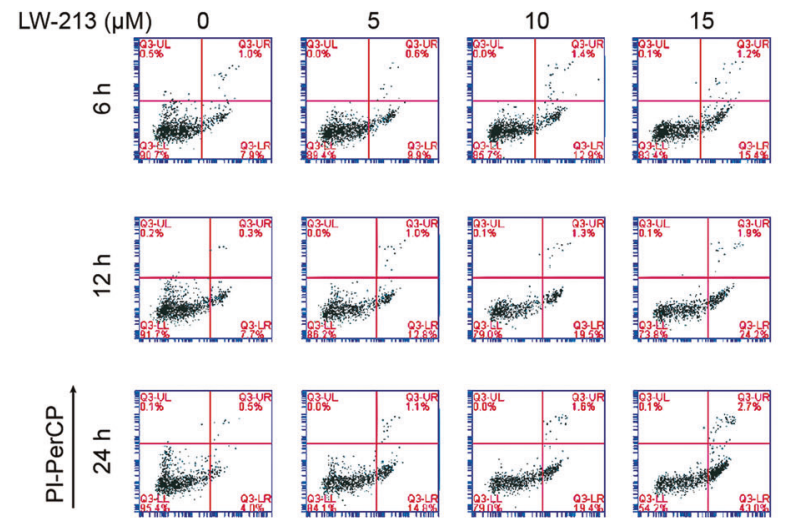

Annexin V-FITC

C

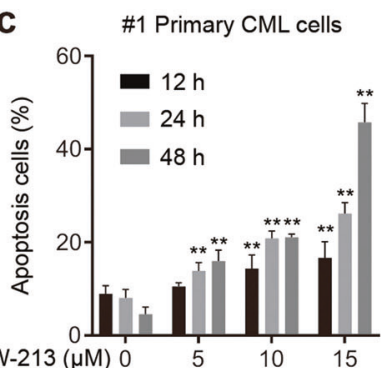

d

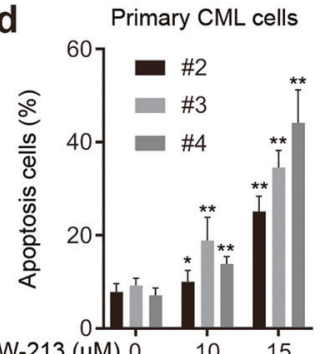

e $\quad L W-213(\mu M) \quad 0 \quad 5 \quad 10 \quad 15$

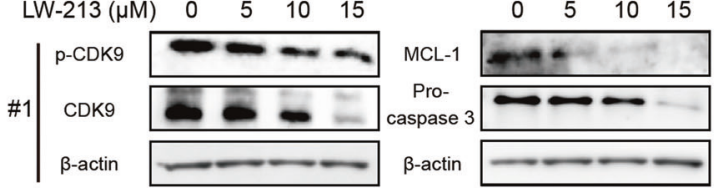

h

LW-213 ( $\mu \mathrm{M})$
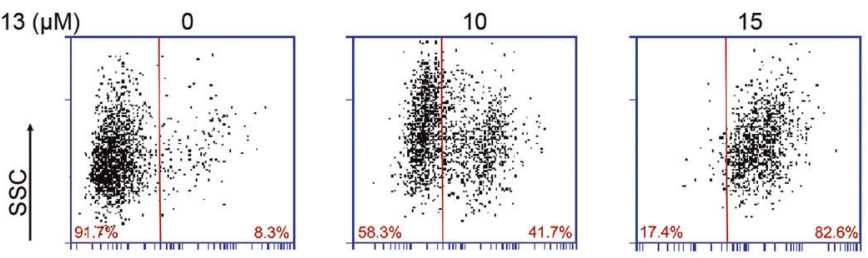

j

CFSE-FITC

$$
\text { LW-21 }
$$

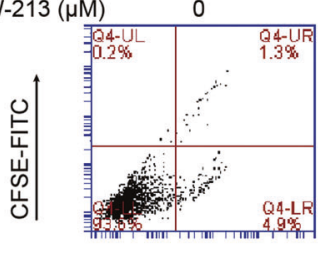

Annexin V-PE

g
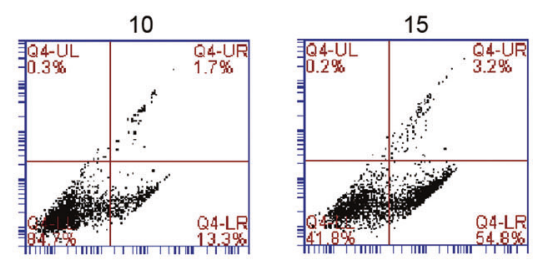

b

$$
\text { LW-213 }(\mu \mathrm{M}) \quad 0 \quad 10
$$
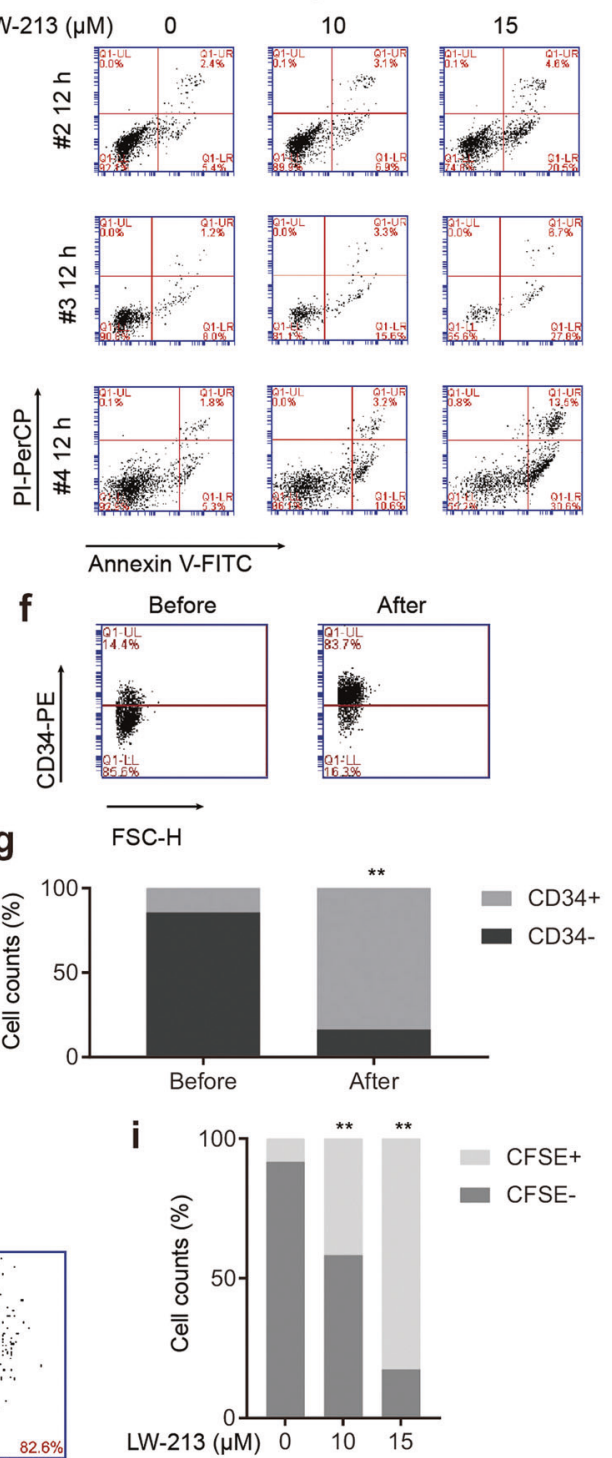

k

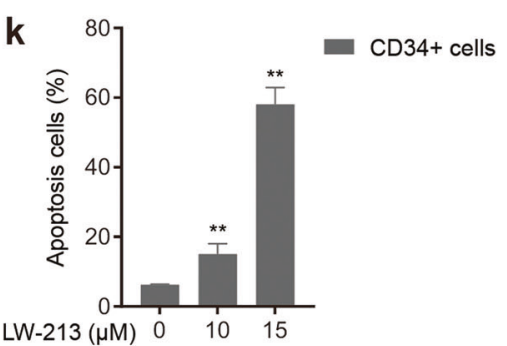

Fig. 6 Apoptosis effects of LW-213 on primary CML cells and CD34+ cells. a-d CML primary cells (samples \#1, \#2, \#3, and \#4) were treated with the indicated concentrations of LW-213, and the apoptosis rates were determined by Annexin V/PI staining. Data represent the mean \pm S.E.M. of three independent experiments. Asterisks denote statistically significant differences compared with untreated cells $\left({ }^{*} P<0.05,{ }^{* *} P<0.01\right)$. Apoptotic cells are positive for Annexin V. e Levels of caspase 3, CDK9, p-CDK9 and MCL-1 in primary cells (sample \#1) were analyzed by Western blotting after treatment with $0,5,10$, and $15 \mu \mathrm{M}$ of LW-213 for $12 \mathrm{~h}$. f, $\mathbf{g ~ C D} 34^{+}$cells were isolated from primary CML cells (sample \#1) by MACS. CD34 ${ }^{+}$cells were gathered after magnetic separation. $\mathbf{h}, \mathbf{i}$ The inhibitory effects of LW- 213 on CD34 ${ }^{+}$cells were determined by the CFSE proliferation assay. CD34 ${ }^{+}$cells were treated with or without $10 \mu \mathrm{M}$ and $15 \mu \mathrm{M} \mathrm{LW}-213$ for $24 \mathrm{~h}$. Asterisks denote statistically significant differences compared with untreated cells $\left({ }^{* *} P<0.01\right)$. j, k Flow cytometric analysis of Annexin V-PE/CFSE-FITC-stained CD34 ${ }^{+}$cells treated with 0,10 and $15 \mu \mathrm{M}$ of LW-213 for $24 \mathrm{~h}$. Data represent the mean \pm S.E.M. of three independent experiments. Asterisks denote statistically significant differences compared with untreated cells $\left({ }^{*} P<0.01\right)$. Apoptotic cells are positive for Annexin $V$ 

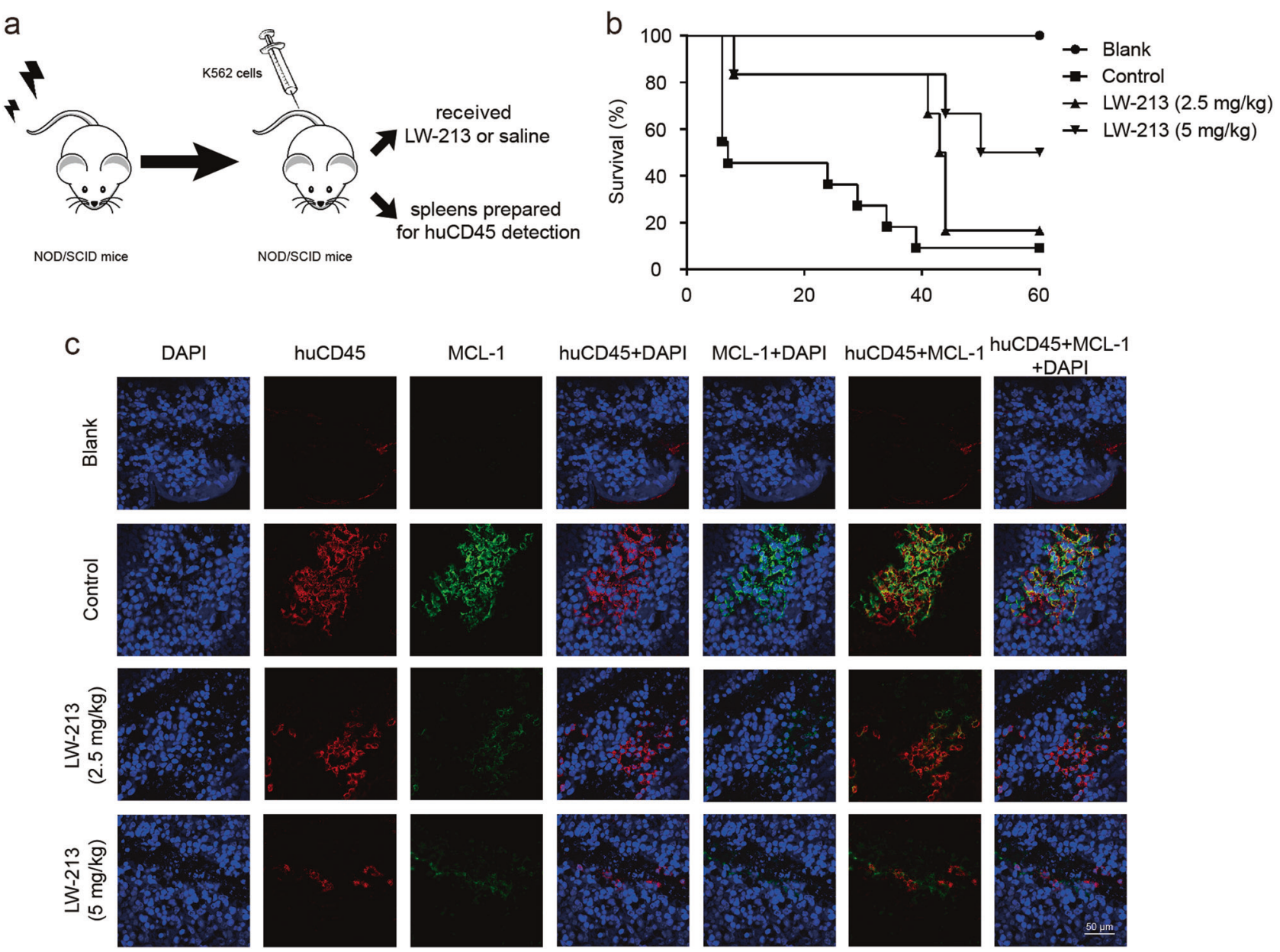

Fig. 7 Anti-CML effects of LW-213 in vivo. a The procedure for establishing the K562 cell-bearing mouse model. b Kaplan-Meier survival plots for K562 cell-bearing NOD/SCID mice are shown. The results are representative of two separate experiments. Animals were observed for 60 days after cell injection. c The infiltration of huCD45 ${ }^{+}$cells and the expression of MCL-1 in the spleens of K562 cell-bearing mice. Spleen samples were collected, and sections were treated with huCD45-PE (red fluorescence) and MCL-1 (labeled with Alexa Fluor 488 goat antirabbit IgG antibody; green fluorescence) antibodies and counterstained with DAPI (blue fluorescence). Images are representative of three independent experiments

as an important factor in resistance to apoptosis [8, 21]. Decreased levels of p-CDK9, p-RNAPII-S2/S5 and MCL-1 were observed after treatment with LW-213. This highlighted the fact that LW-213 induced apoptosis via the CDK9/RNAPII/MCL-1 axis. Our data also showed that LW-213 decreased the expression of CDK9.

The ubiquitin-proteasome pathway and lysosomal degradation are two intracellular systems that degrade proteins [22]. We presumed that LW-213-induced apoptosis is triggered by protein degradation. The lysosome inhibitor $\mathrm{NH}_{4} \mathrm{Cl}$ rescued the cells after LW-213 treatment and reversed the decreases in CDK9 expression. LW-213-induced apoptosis and protein degradation were lysosome-dependent. However, the downregulation of Cyclin B1 and $\mathrm{G} 2 / \mathrm{M}$ phase arrest could not be reversed by $\mathrm{NH}_{4} \mathrm{Cl}$ (Fig. $\mathrm{S} 1 \mathrm{~b}-\mathrm{e})$, and overexpression of CDK9 could not rescue cells from LW-213-induced G2/M arrest (Fig. S1f-i). The downstream proteins of BCR-ABL1, such as STAT5, AKT, and STAT3, could also be decreased after LW-213 treatment, while the expression of BCRABL1 was not influenced by LW-213 (Fig. S1j-k). Thus, LW-213 could inhibit signaling downstream of BCR-ABL1 and induce apoptosis in CML cells.

LW-213-induced apoptosis could be reversed by a lysosome inhibitor. This might indicate the involvement of autophagy in LW213-induced apoptosis and degradation. LW-213 increased the expression of p62 and LC3-II and the ratio of LC3-II/LC3-I, but the effect was modest (Fig. S2a-C). Additionally, 3-MA could not inhibit the apoptosis effects of LW-213 (Fig. S2d-e). 3-MA decreased the expression of LC3-II induced by LW-213, while the reduction in the expression of CDK9, MCL-1 and the proteins downstream of BCR-ABL1 as well as the levels of p-RNAPII-S2 could not be reversed by 3-MA (Fig. S3a-d). It is suggested that LW-213 had modest autophagy effects that were not associated with LW-213-induced protein degradation and apoptosis.

$\mathrm{CML}$ is a clonal myeloproliferative disorder characterized by a $B C R-A B L$ oncogene encoding a constitutively active kinase [23]. Although the majority of patients are treated with TKIs, the disease in CML patients was well controlled, and overall survival was improved significantly [3], a large proportion of CML patients treated with TKls develop drug resistance due to the inability of TKIs to kill leukemia stem cells [23]. CML stem cells that are responsible for the initiation, drug resistance and relapse of CML [23]. Therefore, there is an urgent need for potent therapies against leukemia stem cells in order to cure CML. We found that LW-213 induced apoptosis in CD34 $4^{+}$cells isolated from primary CML cells by MACS in a concentration- and time-dependent manner. It is suggested that the combination of LW-213 and TKIs might be useful for CML treatment. This finding could be of significance in the clinical setting in the future.

Taken together, the data from our study provided evidence of the effectiveness of LW-213 as a CML treatment. The agent showed high antitumor activity against CML cell lines and primary 
CML cells from patients. In conclusion, LW-213 may be a promising treatment option for CML therapy.

\section{ACKNOWLEDGEMENTS}

This work was supported by the National Natural Science Foundation of China [No. 81673461, 81873046 and 81830105], the Drug Innovation Major Project [2017ZX09301014, 2018ZX09711001-003-007], the Project Program of State Key Laboratory of Natural Medicines, China Pharmaceutical University [No. SKLNMZZCX201823], the Social Development Project of Jiangsu Provincial Science and Technology Department [NO. BE2018711], and the "Double First-Class" University project [CPU 2018GF11, CPU2018GF05].

\section{AUTHOR CONTRIBUTIONS}

$\mathrm{XL}$ designed and performed the research; $\mathrm{PH}$ analyzed the data and wrote the paper $\mathrm{HL}$ and XXY performed the research and analyzed the data; XYW and YJQ performed the research; ZYW collected data and performed the statistical analysis; $\mathrm{HZW}$ and MYZ collected and analyzed data; and QLG and HH conceptualized the project and directed the experimental design and data analysis.

\section{ADDITIONAL INFORMATION}

The online version of this article (https://doi.org/10.1038/s41401-019-0270-4) contains supplementary material, which is available to authorized users.

Competing interests: The authors declare no competing interests.

\section{REFERENCES}

1. Apperley JF. Chronic myeloid leukaemia. Lancet. 2015;385:1447-59.

2. Aichberger KJ, Mayerhofer M, Krauth MT, Skvara H, Florian S, Sonneck K, et al. Identification of mcl-1 as a BCR/ABL-dependent target in chronic myeloid leukemia (CML): evidence for cooperative antileukemic effects of imatinib and $\mathrm{mcl}-1$ antisense oligonucleotides. Blood. 2005;105:3303-11.

3. Holyoake TL, Vetrie D. The chronic myeloid leukemia stem cell: stemming the tide of persistence. Blood. 2017;129:1595-606.

4. Coppo P, Flamant S, De Mas V, Jarrier P, Guillier M, Bonnet ML, et al. BCR-ABL activates STAT3 via JAK and MEK pathways in human cells. $\mathrm{Br} J$ Haematol. 2006;134:171-9.

5. Polier G, Ding J, Konkimalla BV, Eick D, Ribeiro N, Kohler R, et al. Wogonin and related natural flavones are inhibitors of CDK9 that induce apoptosis in cancer cells by transcriptional suppression of Mcl-1. Cell Death Dis. 2011;2:e182.

6. Gressel S, Schwalb B, Decker TM, Qin W, Leonhardt H, Eick D, et al. CDK9-dependent RNA polymerase II pausing controls transcription initiation. Elife. 2017;6:e29736.
7. Thomas D, Powell JA, Vergez F, Segal DH, Nguyen NY, Baker A, et al. Targeting acute myeloid leukemia by dual inhibition of $\mathrm{PI} 3 \mathrm{~K}$ signaling and Cdk9-mediated Mcl-1 transcription. Blood. 2013;122:738-48.

8. Akgul C. Mcl-1 is a potential therapeutic target in multiple types of cancer. Cell Mol Life Sci. 2009;66:1326-36.

9. Hussain SRA, Cheney CM, Johnson AJ, Lin TS, Grever MR, Caligiuri MA, et al. Mcl-1 is a relevant therapeutic target in acute and chronic lymphoid malignancies: down-regulation enhances rituximab-mediated apoptosis and complementdependent cytotoxicity. Clin Cancer Res. 2007;13:2144-50.

10. Zhao L, Miao HC, Li WJ, Sun Y, Huang SL, Li ZY, et al. LW-213 induces G2/M cell cycle arrest through AKT/GSK3beta/beta-catenin signaling pathway in human breast cancer cells. Mol Carcinog. 2016;55:778-92.

11. Chen $\mathrm{Y}$, Hui $\mathrm{H}$, Yang $\mathrm{H}$, Zhao K, Qin $\mathrm{Y}, \mathrm{Gu}$ C, et al. Wogonoside induces cell cycle arrest and differentiation by affecting expression and subcellular localization of PLSCR1 in AML cells. Blood. 2013;121:3682-91.

12. Lonetti A, Antunes IL, Chiarini F, Orsini E, Buontempo F, Ricci F, et al. Activity of the pan-class I phosphoinositide 3-kinase inhibitor NVP-BKM120 in T-cell acute lymphoblastic leukemia. Leukemia. 2014;28:1196-206.

13. Deininger MW, Goldman JM, Melo JV. The molecular biology of chronic myeloid leukemia. Blood. 2000;96:3343-56.

14. Khalil R. Ubiquitin-Proteasome Pathway and Muscle Atrophy. Adv Exp Med Biol. 2018;1088:235-48.

15. Hall $\mathrm{CP}$, Reynolds $\mathrm{CP}$, Kang $\mathrm{MH}$. Modulation of glucocorticoid resistance in pediatric T-cell acute lymphoblastic leukemia by increasing BIM expression with the PI3K/mTOR inhibitor BEZ235. Clin Cancer Res. 2016;22:621-32.

16. Yang K, Fu LW. Mechanisms of resistance to BCR-ABL TKIs and the therapeutic strategies: a review. Crit Rev Oncol Hematol. 2015;93:277-92.

17. Zeijlemaker W, Grob T, Meijer R, Hanekamp D, Kelder A, Carbaat-Ham JC, et al. CD34(+)CD38(-) leukemic stem cell frequency to predict outcome in acute myeloid leukemia. Leukemia. 2019;33:1102-12.

18. Kidd PM. Bioavailability and activity of phytosome complexes from botanical polyphenols: the silymarin, curcumin, green tea, and grape seed extracts. Alter Med Rev. 2009;14:226-46.

19. Yang Y, Liu K, Yang L, Zhang G. Bladder cancer cell viability inhibition and apoptosis induction by baicalein through targeting the expression of antiapoptotic genes. Saudi J Biol Sci. 2018;25:1478-82.

20. Hu Y, Yang Y, You QD, Liu W, Gu HY, Zhao L, et al. Oroxylin A induced apoptosis of human hepatocellular carcinoma cell line HepG2 was involved in its antitumor activity. Biochem Biophys Res Commun. 2006;351:521-7.

21. Warr MR, Shore GC. Unique biology of Mcl-1: therapeutic opportunities in cancer Curr Mol Med. 2008;8:138-47.

22. Zhan J, He J, Zhou Y, Wu M, Liu Y, Shang F, et al. Crosstalk between the autophagy-lysosome pathway and the ubiquitin-proteasome pathway in retinal pigment epithelial cells. Curr Mol Med. 2016;16:487-95.

23. Zhou H, Xu R. Leukemia stem cells: the root of chronic myeloid leukemia. Protein Cell. 2015;6:403-12. 